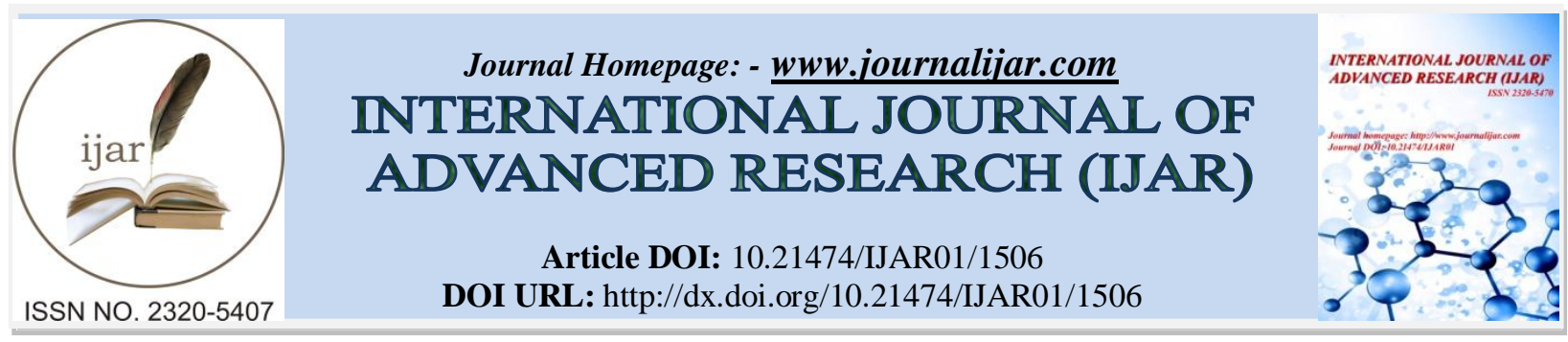

RESEARCH ARTICLE

\title{
SELECTIVE SEPARATION OF IRON (III) FROM IMMOBILIZATION OF CATION EXCHANGER RESIN WITH TRIOCTYPHOSPHINE OXIDE SORBENT.
}

\author{
S. H. Burungale. A.V. Mali \\ Department of Chemistry, Yashwantrao Chavan College of Science, Karad-415124, India.
}

\section{Manuscript Info}

Manuscript History

Received: 12 July 2016

Final Accepted: 16 August 2016

Published: September 2016

Key words:-

Synthesis of immobilization of TOPO

with cation exchanger resin

Determination of Fe (III); Analysis of

real samples.

\begin{abstract}
Reversed - phase extraction chromatography (RPEC) is an extremely versatile technique and has been applied successfully to the separation of various metals from organic compounds. In RPEC trioctylphosphine oxide (TOPO) has been extensively used for the extraction chromatographic separation of many metal ions. This paper describes systematic investigation of the extraction chromatographic separation of Iron on a Cation exchanger resin column with triotylphosphine oxide as the stationary phase. Methods are presented for the separation of iron from a large number of elements in multi- component mixtures. The method has been extended to the determination of Iron in real samples.
\end{abstract}

Copy Right, IJAR, 2016,. All rights reserved.

\section{Introduction:-}

The interest in the separation and determination of trace metals in natural waters has increased in the last decades because of the environmental problems and public health studies. Iron in small amounts is essential for humans and animals. Iron deficiency caused anemia and much may cause several health problems (cancer, heart disease, arthritis, diabetes and liver diseases) [1]. Iron was restricted to $2 \mathrm{mg} \mathrm{L}-1$ by World Health Organization [2] and 200 $\mu \mathrm{gL}-1$ by European Legislation [3]. Due to the very low concentration of iron and the interfering effect of the matrix, its determination demand very sensitive analytical techniques [4-6]. Separation and pre concentration were applied to overcome these difficulties. Many procedures are well characterized for such a purpose [7-8. Of all, solid phase extraction (SPE) has attracted a great attention owing to its simple operation, rapid phase separation, no emulsification, high enrichment factor and for easily automation. Organic chelating resins [9], polymer inclusion sorbents [10], modified nanometer-sized alumina [11], C18-bonded silica gel [12], controlled-pore glass [13], activated carbon [14], ion exchange resins [15], thermal modified kaolinite [16], polymeric resin [17-26].

\section{Experimental:- \\ Apparatus:-}

Graduated apparatus of standard calibration were used for measurements. All glassware's were washed with nitric acid $(5 \% \mathrm{v} / \mathrm{v})$ new glassware's were allowed to stand for several hours in nitric acid. After three rinses with distilled water, and the glassware's were stored under dust free conditions.

\section{Equipments:-}

Spectrophotometer: Systronic India Ltd. Model No,166, pH meter, Digital Balance 


\section{Reagents:-}

All reagents used were of analytical grade. Double distilled water was used for solution preparation. The reagents used in this study were immobilization of baker yeast with trioctyl phosphine oxide polymeric resin, Ferric Chloride (99.5\%, hydrochloric acid $(37 \%$.

\section{Stock solution:-}

Ferric nitrate solution. Dissolve 36.2 grams of reagent grade $\mathrm{Fe}\left(\mathrm{NO}_{3}\right)_{3}-9 \mathrm{H}_{2} \mathrm{O}$ in $500 \mathrm{ml}$ of one per cent $\mathrm{HN} 0_{3}$ to prepare a solution that contains approximately $10 \mathrm{mg}$ of iron(lll) per $\mathrm{ml}$. Standardize the solution versus potassium dichromate after reducing the iron(1ll) to iron(ll) with stannouschloride and mercuric chloride. Working solutions for trace analysis were prepared daily by appropriate dilutions.

\section{Preparation of column extractant.:-}

The chromatographic column was made of a borosilicate glass tube, bore $8 \mathrm{~mm}$, length $25 \mathrm{~cm}$, fitted with glass wool plug at the bottom. 0.1 M TOPO solution was prepared by dissolving $1.94 \mathrm{~g}$ of reagent in $25 \mathrm{ml}$ of water. Dowex-50 resin $(\mathrm{BDH})(60-120 \mathrm{mesh})$ was dried at $120^{\circ} \mathrm{C}$ for $2-3$ hours and stored in a desiccators. Some of the Dowex -50 resin and methylene blue indicator were mixed with each other and was packed in a U-tube through which was passed a stream of dry nitrogen that had been bubbled through a $20 \mathrm{ml}$ of dimethlydichloro silane (DMCS) vapour was continued for 3-4 h. the Dowex -50 resin containing TOPO was then washed with water and dried. A slurry of the coated Dowex -50 resin in distilled water was prepared by centrifugation at $2000 \mathrm{rpm}$ and be the coated resin was packed into the chromatographic column to given a bed height of $6 \mathrm{~cm}$. The bed was then covered with a glass wool plug and the column extractant

\section{General procedure:-}

$100 \mu \mathrm{g}$ of Fe (III) was mixed with Hydrochloric acid in the concentration range of $0.05 \mathrm{M}$ to $2.4 \mathrm{M}$ in a total volume of $10 \mathrm{~mL}$. The solution was then passed through cation exchange resin with TOPO resin column pre-conditioning with same concentration of hydrochloric acid as that of the sample solution at flow rate of $0.5 \mathrm{~mL} / \mathrm{min}$. The column was then washed with the same concentration of hydrochloric acid. The sorbed Fe (III) was then eluted with different eluting agents at the flow rate of $0.5 \mathrm{~mL} / \mathrm{min}$. Total $25 \mathrm{~mL}$ fractions were collected and the Fe (III) content was determined spectrophotometerically with potassium thiocyanate $[17,18]$ at $490 \mathrm{~nm}$.

\section{Results and Discussion:-}

Adsorption of Fe (III) on cation exchange resin with TOPO resin as a function of Hydrochloric acid concentration. Sorption studies of Fe (III) were carried out from hydrochloric acid medium. The concentration of Hydrochloric acid varied from $0.05 \mathrm{M}$ to $2.4 \mathrm{M}$. After sorption, Fe (III) was eluted with $2.0 \mathrm{M}$ hydrochloric acid. It was found that there is quantitative (100\%) sorption of Fe (III) from $0.5 \mathrm{M}$ to $2 \mathrm{M}$ hydrochloric acid concentration. Further decrease in hydrochloric acid concentration there is decrease in sorption of Fe (III) shown in Table 1, Figure 1. The subsequent sorption studies of Fe (III) were carried out with 1.4M hydrochloric acid.

\section{Elution study of Fe (III) with various eluting agents:-}

$100 \mu \mathrm{g}$ of Fe (III) in $0.05 \mathrm{M}$ to $2.4 \mathrm{M}$ hydrchloric acid was sorbed on cation exchange resin with TOPO resin. After sorption, Fe(III) was eluted from column with various eluents such as hydrochloric acid ,hydrobromic acid, sulfuric acid,perchloric acid and acetic acid. The concentration of eluting agent varied from $0.05 \mathrm{M}$ to 4.0 M. Various elution studies revealed that, there is quantitative elution of $\mathrm{Fe}(\mathrm{III})$ with $25 \mathrm{~mL}$ of 4.0 to $8.0 \mathrm{M}$ hydrobromic acid and 1.0 to 4.0 M sulfuric acid whereas perchloric acid and acetic acid were found to be inefficient eluents. Further elution studies of $\mathrm{Fe}(\mathrm{III})$ in this work were carried out with 4.0 M hydrochloric acid.

\section{Sorption of Fe (III) on cation exchange resin with TOPO resin as a Function of hydrochloric acid concentration:-}

Sorption studies of Fe (III) were carried out from hydrochloric acid medium. The concentration of hydrochloric acid varied from $0.05 \mathrm{M}$ to $2.4 \mathrm{M}$. After sorption, Fe(III) was eluted with 4.0 M hydrochloric acid. It was found that there is quantitative (100\%) sorption of Fe(III) from $0.5 \mathrm{M}$ to $2 \mathrm{M}$. hydrochloric acid concentration. Further decrease in hydrochloric acid concentration with decrease in sorption of Fe (III). The subsequent sorption studies of Fe(III) were carried out with 1.4 M. hydrochloric acid 
Table 1:- Sorption of Fe (III) as a function of hydrochloric acid concentration.

\begin{tabular}{|c|c|}
\hline Hydrochloric acid Concentration M & Adsorption of Fe (III) \% \\
\hline 0.05 & 94 \\
\hline 0.06 & 98 \\
\hline 0.07 & 99 \\
\hline 0.08 & 99 \\
\hline 0.1 & 100 \\
\hline 0.2 & 100 \\
\hline 0.4 & 100 \\
\hline 0.6 & 100 \\
\hline 0.8 & 100 \\
\hline 1.0 & 100 \\
\hline 1.2 & 98 \\
\hline 1.4 & 77 \\
\hline 1.6 & 56 \\
\hline 1.8 & 10 \\
\hline 2.00 & 00 \\
\hline
\end{tabular}

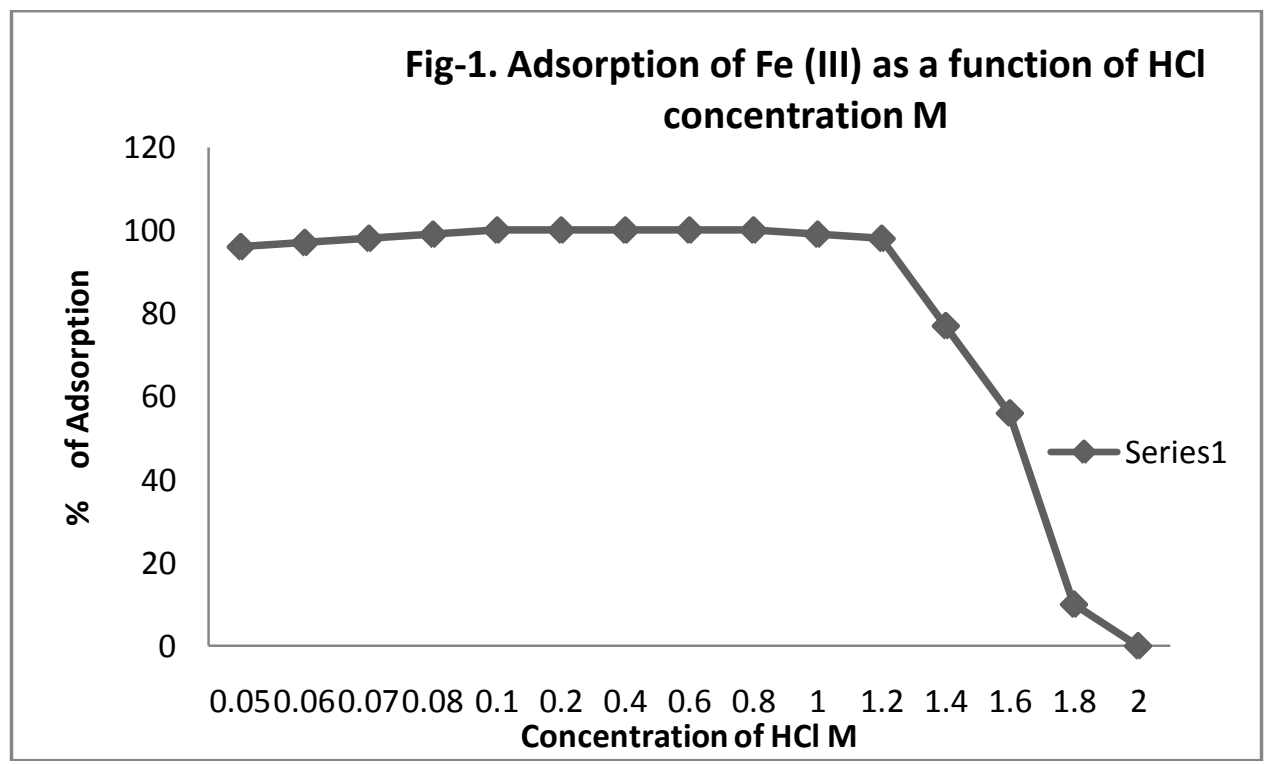

Fig 1:- Adsorption of Fe (III) as a function of Hydrochloric acid concentration M.

\section{Effect of varying concentration of $\mathrm{Fe}(\mathrm{III})$ :-}

The capacity of the cation exchange resin with TOPO resin for Fe (III). was evaluated using $4.0 \mathrm{~g}$ of the cation exchange resin with TOPO resin and sorption studies were carried out from $1.4 \mathrm{M}$ hydrochloric acid and $4.0 \mathrm{M}$ hydrochloric acid as an eluent. The volume of Fe (III) sample solution was 10mL. The concentration of Fe(III) was varied from 100-2000 $\mu \mathrm{g}$ of Fe(III). Per10 mL of solution. The result shows that sorption of Fe (III) is quantitative up to $1500 \mu \mathrm{g} / 10 \mathrm{~mL}$. Further increase in concentration of Fe(III) there is decrease in percentage sorption as shown in Table 2, The capacity of the cation exchange resin with TOPO resin for Fe (III) was found to be $0.87 \pm 0.01$ $\mathrm{mmol} / \mathrm{g}$ cation exchange resin with TOPO resin. 
Table 2:- Effect of varying concentration of Fe(III).

\begin{tabular}{|c|c|}
\hline Concentration of Iron $\mu \mathrm{g}$ & Adsorption of Fe (III). \\
\hline 100 & 100 \\
\hline 200 & 100 \\
\hline 400 & 100 \\
\hline 600 & 100 \\
\hline 800 & 100 \\
\hline 1000 & 100 \\
\hline 1200 & 80 \\
\hline 1400 & 65 \\
\hline 1600 & 45 \\
\hline 1800 & 30 \\
\hline 2000 & 20 \\
\hline
\end{tabular}

\section{Column reuse:-}

To test the long-term stability of the column containing the modified resin, successive sorption and elution cycles were carried out by passing Fe (III) solution through the column at the optimum flow rate, then eluted. The procedure was carried out several times and the stability of the column was assessed by monitoring the change in the recoveries of the sorbed Fe (III). The results of 100 sorption/desorption cycles indicate that, the recovery decreases by $\leq 3 \%$ reflecting good stability of the modified resin

\section{Determination of Iron in real sample:-}

Geological sample: $0.550 \mathrm{~g}$ of Hematite ore was heated up to $700 \mathrm{0C}$ for $2 \mathrm{hrs}$ to remove organic matter and was treated with concentrated $\mathrm{HNO}_{3}$, the mixture was heated to moist dryness. The procedure was repeated for thrice and extracted with distilled deionized water. The hot solution was filtered, diluted and $\mathrm{Fe}$ (III) Content was determined by proposed method. The obtained results are shown in Table 3.

Table 3:- Determination of Fe (III). From geological samples.

\begin{tabular}{|c|c|c|c|}
\hline & \multicolumn{3}{|c|}{ Amount of Fe(III). found By } \\
\hline Sample & AAS & Proposed Method & Standard deviation $( \pm 2 \%)$ \\
\hline Hematite ore & $43 \%$ & $42.8 \%$ & $0.2 \%$ \\
\hline
\end{tabular}

\section{Determination of $\mathbf{F e}$ (III) in pharmaceutical samples:-}

A tablet of drug or vitamin was digested using $5 \mathrm{~mL}$ of concentrated $\mathrm{HNO}_{3}$ and dryness. After cooling, the residue was dissolved with another $5 \mathrm{ml}$ of the acid. The solution was gently evaporated on a water bath till a residue was again left. It was heated with $50 \mathrm{~mL}$ of doubly distilled water, filtered off and completed to $100 \mathrm{~mL}$ in a calibrated flask. After adjusting the $\mathrm{pH}$, the procedure for the determination of $\mathrm{Fe}(\mathrm{III})$ was applied (column mode). The recovered amount of $\mathrm{Fe}$ (III) was determined and the results are listed in Table 5.

\begin{tabular}{|c|c|c|}
\hline Pharmaceutical tablets & Mineral Composition mg/tablet & Recovery \% Fe(III) \\
\hline Gerimax & $\begin{array}{l}\mathrm{Mg} \text { (II) } 150 \mathrm{mg}, \mathrm{Fe}(\mathrm{II}) 14 \mathrm{mg} \\
\mathrm{Mn}(\mathrm{II}) 2.5 \mathrm{mg}, \mathrm{Zn} \text { (II) } 15 \mathrm{mg} \\
\mathrm{Cr}(\mathrm{III}) 0.05 \mathrm{mg}\end{array}$ & $\begin{array}{l}14 \pm 0.02 \\
100 \%\end{array}$ \\
\hline Centrum & $\begin{array}{l}\mathrm{Ca}(\mathrm{II}) 162 \mathrm{mg}, \mathrm{Mg} \text { (II) } 100 \mathrm{mg} \\
\text {,Fe(II) 27mg, } \\
\mathrm{Mn} \text { (II)7.5mg, Zn (II) } 22.5 \mathrm{mg} \\
\text { 7.5mg, Cu } 3.00 \mathrm{mg} . \\
\end{array}$ & $\begin{array}{l}26.75 \pm 0.02 \\
99.15 \%\end{array}$ \\
\hline Totavit & $\begin{array}{l}\text { Cr } 25 \mathrm{mg}, \mathrm{Mn} 2.5 \mathrm{mg}, \text { Fe } 18 \mathrm{mg} \text {, } \\
\mathrm{Cu} 2.00 \mathrm{mg} \mathrm{Zn} 15 \mathrm{mg}\end{array}$ & $\begin{array}{l}17.88 \pm 0.02 \\
99.65 \%\end{array}$ \\
\hline
\end{tabular}

\section{Conclusion:-}

A simple, rapid and selective column chromatographic method for the separation and determination of $\mathrm{Fe}$ (III) from other toxic metal ions using cation exchange resin with TOPO resin in hydrochloric acid medium has been developed. In addition to adopting a simple method, the method extends for the determination of Fe (III) from real samples. The results obtained by this method were in good agreement with AAS results. 


\section{References:-}

1. Niederau, C.; Fischer, R.; Purschel, A.; Stremmel, W.; Haussinger, D Gastroenterology. 1996, 110, 1107-1119.

2. WHO, Rolling revision of the WHO guidelines for drinking water quality, Nutrient minerals in drinking-water and the potential health consequences of long-term consumption of demineralized and remineralized and altered mieral content drinking-waters, 2003.

3. European Community, Directive 98/83/EC on the quality of water intended for human consumption, 1998.

4. Ceccarini, A. Cecchini, I.; Fuoco, R.. Microchem. J. 2005, 79, 21-24.

5. Elci, L.; Kartal A. A.; Soylak, M. J. Hazard. Mat. 2008, 153, 454-461.

6. Mortada, W.I.; Hassanien, M. M.; El-Asmy, A. A.. Anal. Methods, 2013, 5, 530-535

7. Xia, L.B.; Wu, Y.L.; Jiang, Z.C.; Li, S.Q.; Hu, B J. Environ. Anal. Chem. 2003, 83, 953-962.

8. Kara, D.; Alkan, M. Talanta, 2001, 55, 415-423

9. Mondal, B.C.; Das, D.; Das, A.K. Talanta 2002, 56, 145-152.

10. Scindia, Y.M.; Pandey, A.K.; Reddy, A.V.R.; Manohar, S.B. Anal. Chem. 2002, 74, 4204-4212.

11. Pu, X.L.; Jang, Z.C.; Hu, B.; Wang, H.BJ. Anal. At. Spectrom. 2004, 19, 984.

12. Mahmoud, M.E.; Gohar, G.A. Talanta 2000, 51, 77-87.

13. Bruhn, C.G.; Pino, F.E.; Campos, V.H.; N’obrega, J.AAnal. Bioanal. Chem. 2002, 374, 131.

14. Cerutti, S.; Silva, M.F.; G'asquez, J.A.; Olsina, R.A.; Martinez, L.D. Spectrochim. Acta Part B 2003, 58, 43-50.

15. Hassanien, M.M.; Hassan, A.M.; Mortada, W.I., El-Asmy A.A. Am. J. Anal. Chem. 2011, 2, 697-709.

16. Afzali, D.; Taher, M.A.; Mostafavi, A.; Mobarakeh, S.Z.M. Talanta 2005, 65, 476-480.

17. Taher, M. A. Talanta 2000, 52, 301-309.

18. Taher, M.A. Analyst 2000, 125, 1865-1868.

19. Mortada, W.I.; Hassanien, M.M.; El-Asmy A.A. J. Trace Elements in Medicine and Biology, 2013, 27, 267272.

20. Huang, W.H.; Hu, B.; Xiong, H.C.; Jiang, Z.C.. J. Anal. Chem. 2000, 367, 254.

21. Xiong, H.C.; Hu, B.; Peng, T.Y.; Chen, S.Z.; Jiang, Z.C. Anal. Sci. 1999, 15, 737.

22. B. S. Mohite, B. E. Mahadik \& S. H. Burungale, Res. J. Chem. \& Environment, 1998,2, 43-45.

23. B. S. Mohite, S. H. Burungale, B. E. Mahadik \& D. N. Zambare, Ind. J. Chem., 1998 37A, 1035-37.

24. B. S. Mohite \& S. H. Burungale, J.Chemical \& Environ. Research, 19987(3-4), 205-212.

25. S. H. Burungale International Journal of Analytical and Bioanalytical Chemistry 2015; 5(2): 48-52 